\title{
A 63-year-old man with chronic spontaneous urticaria
}

\author{
Gordon L. Sussman MD, Jacques Hebert MD, F. Estelle R. Simons MD
}

1 63-year-old man weighing $80 \mathrm{~kg}$ was referred to a university hospital allergy clinic with a 16-year history of generalized hives (itchy wheals with associated swelling) that occurred almost every day (Figure 1). Individual wheals lasted less than 24 hours. The patient restricted his diet because he thought that certain foods might be triggering the hives. He had difficulty sleeping because of constant, severe itching. His productivity at work, which involved cognitive activity and frequent travel, had decreased. His quality of life was poor.

The patient's medications for the hives included hydroxyzine 25-200 mg total daily dose, supplemented with various nonprescription $\mathrm{H}_{1}$-antihistamines as needed, and prednisone 5-40 mg/d. He was also taking daily doses of rosuvastatin $20 \mathrm{mg}$, valsartan 80-160 mg and clopidogrel $75 \mathrm{mg}$ following a myocardial infarction, for which he had undergone angioplasty with a stent. His history also included reduced bone density and surgical repair of an abdominal aortic aneurysm.

Results of blood tests ordered in the past by his family physician and several consultants to rule out underlying diseases had consistently been within normal limits (see Appendix 1, at www.cmaj.ca/ lookup/suppl/doi:10.1503/cmaj.150154/-/DC1).

In the previous year, the patient had received five courses of prednisone and had visited the emergency department of his community hospital several times because of debilitating exacerbations of hives and intolerable itching.

First-generation $\mathrm{H}_{1}$-antihistamines did not consistently relieve his itching and whealing, although they caused sedation. At different times, besides hydroxyzine, the patient took diphenhydramine 25-200 mg total daily dose or doxepin 25-125 mg total daily dose, as well as second-generation $\mathrm{H}_{1}$-antihistamines, including cetirizine $10-40 \mathrm{mg}$ and loratadine $10 \mathrm{mg}$.

From time to time, an $\mathrm{H}_{2}$-antihistamine (ranitidine $300 \mathrm{mg} / \mathrm{d}$ ) or a leukotriene antagonist (montelukast $10 \mathrm{mg} / \mathrm{d}$ ) had been added, without relief. Similarly, trials of hydroxychloroquine $400 \mathrm{mg} / \mathrm{d}$ followed by cyclosporine $300 \mathrm{mg} / \mathrm{d}$, each used for two months, gave no relief. Intravenous gamma globulin treatment gave some relief, but it was stopped because of a hemolytic reaction. A chronologic account of the patient's medication history is found in Appendix 1.

On examination in the allergy clinic, the patient had generalized confluent hives. His complete blood count, erythrocyte sedimentation rate and thyroid antibody test results (antithyroperoxidase) were within normal limits. No other investigations were performed.

The patient was asked to monitor hives and itching daily for one week using a validated weekly Urticaria Activity Score (UAS7) (Box 1). His score of 42, the maximum weekly UAS7 score, indicated severe disease.

Given the poor response to previous medications, omalizumab $150 \mathrm{mg}$ was administered monthly by subcutaneous injection. Cetirizine $20 \mathrm{mg} / \mathrm{d}$ was started again. Prednisone was continued in tapering doses. Within a week, the hives and itching had almost disappeared, as reflected in his daily UAS7 scores. Subsequently, the patient stopped taking prednisone and maintained low daily UAS7 scores. His sleep quality, sleep duration and work productivity improved. He responded well to each omalizumab injection; however, breakthrough urticaria often occurred six to eight weeks after the injections.

\section{KEY POINTS}

- According to the new urticaria classification system, "chronic spontaneous urticaria" has replaced the term "chronic idiopathic urticaria."

- New validated, easy-to-use instruments, such as the Urticaria Activity Score (UAS7), are available to help patients quantify urticaria and itching on a daily basis.

- Based on a 2014 international urticaria guideline, the recommended first-line treatment of chronic spontaneous urticaria is a nonimpairing, nonsedating $\mathrm{H}_{1}$-antihistamine, such as desloratadine or cetirizine.

- Recommended second-line treatment is up-dosing (to two, three or four times the licensed dose) with a nonimpairing, nonsedating $\mathrm{H}_{1}$-antihistamine, such as desloratadine or cetirizine.

- Recommended third-line treatment of refractory chronic spontaneous urticaria includes omalizumab by monthly subcutaneous injection until remission occurs, or cyclosporine, although the latter appears to be less effective for inducing remission and may cause more adverse events. 
Three years later, the chronic spontaneous urticaria again became severe and difficult to treat, requiring longer courses and higher doses of prednisone. The omalizumab dose was increased to $300 \mathrm{mg}$ given monthly. Urticaria control, confirmed by low UAS7 scores, was subsequently maintained at this dosage.

\section{Discussion}

Chronic urticaria is urticaria that lasts for more than six weeks. It affects $0.5 \%-1 \%$ of the general population. ${ }^{1,2}$ Although about $50 \%$ of patients experience spontaneous remission within a year after onset, $10 \%-25 \%$ have recurrent urticaria for five years or more. Concomitant angioedema occurs in as many as two-thirds of patients.

According to expert international consensus, ${ }^{1}$ the new term "chronic spontaneous urticaria," reflecting an endogenous, unidentifiable cause, has replaced the term "chronic idiopathic urticaria" (Box 2). Also, the term "chronic inducible urticaria" has replaced "chronic physical urticaria."

Chronic inducible urticaria can occur independently from or concomitantly with chronic spontaneous urticaria. The thresholds for common stimuli that induce whealing, such as dermographism or cold, can now be tested using standardized instruments. ${ }^{2,3}$

In contrast, acute urticaria, which affects as many as $30 \%$ of the general population, lasts from a few hours or days to six weeks and remits spontaneously. Often it is triggered by a viral infection or exposure to an allergen, especially in children. Relevant allergy tests are warranted if the history suggests atopy. ${ }^{1,2}$

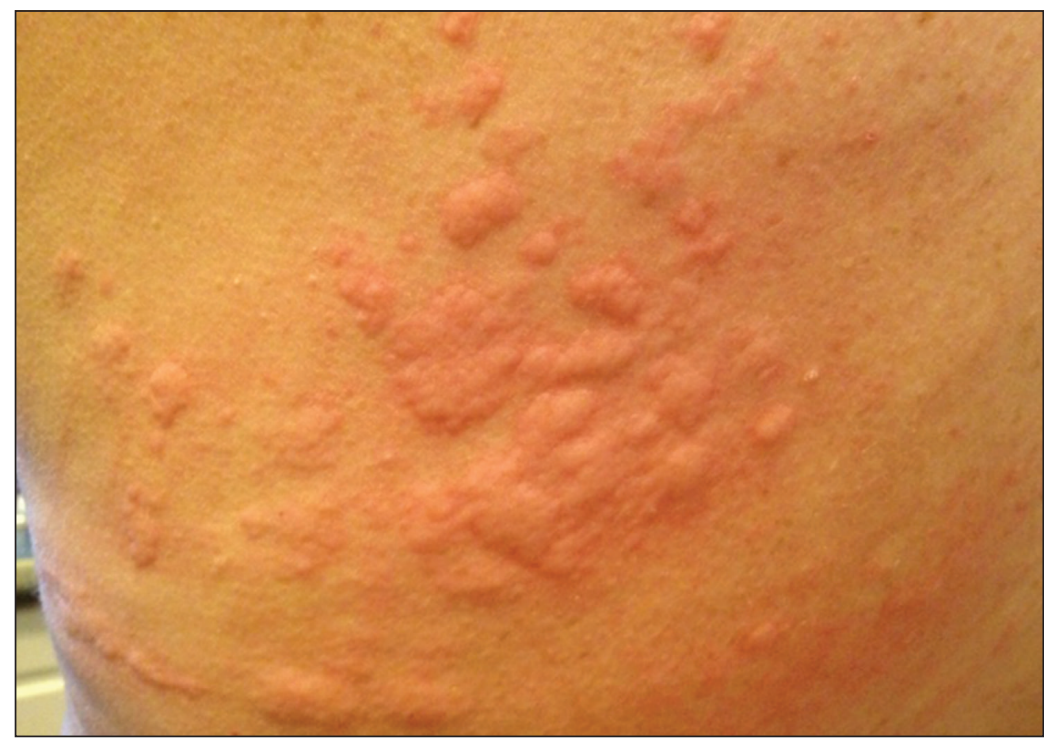

Figure 1: Typical appearance of urticaria with wheals (some of which are confluent) and flares (erythema) similar to those experienced by the patient.

\section{Differential diagnosis}

The differential diagnosis of urticaria can be simplified by using a practice algorithm ${ }^{3}$ (Figure 2).

Patients with chronic urticaria whose wheals last less than two hours should be tested for chronic inducible urticaria, from, for example, dermographism or cold. ${ }^{1}$ Those presenting with painful wheals lasting longer than 24 hours require a biopsy of a lesion to rule out urticarial vasculitis. Patients presenting with urticaria associated with fever, bone pain, malaise or fatigue should be investigated for auto-inflammatory diseases, while those presenting with angioedema or swelling without wheals or pruritus require investigation for hereditary angioedema, angiotensinconverting enzyme inhibitor-induced angioedema and other types of bradykinin-induced swelling. 2,3

\section{Pathophysiology}

Chronic spontaneous urticaria often has an autoimmune cause. Antibodies to the $\alpha$ component of the immunoglobulin $\mathrm{E}$ ( $\mathrm{IgE}$ ) receptor on mast cells are identified in about $45 \%$ of affected patients $;{ }^{1}$ however, this test is neither widely available nor specific for chronic spontaneous urticaria. Thyroid antibodies are found in about $25 \%$ of patients with chronic spontaneous urticaria, but treatment of the thyroid disease does not typically relieve the urticaria. ${ }^{2,3}$ Although most patients with chronic spontaneous urticaria never have a specific cause identified, this does not affect their treatment or outcome.

\section{Investigations}

In chronic spontaneous urticaria, by consensus of experts, only a few routine diagnostic tests are recommended. A thorough history and physical examination are essential. Limited testing might consist of a complete blood count and measurement of inflammatory markers, including C-reactive protein or the erythrocyte sedimentation rate. This approach identifies patients who need further investigations. Allergy tests are usually not indicated, because food allergens seldom trigger chronic urticaria., ${ }^{2,3}$

\section{New instruments used in assessment}

Chronic spontaneous urticaria causes substantial morbidity and negatively affects sleep, work, school and social activities. New instruments have been developed to quantify disease severity. Urticaria guidelines recommend use of the validated UAS7 score, in which the patient records severity of itching and number of wheals once daily (Box 1). A weekly score of less than 7 indicates complete control of disease, and a weekly score greater than 28 indicates severe disease 
activity. In clinical practice, use of the UAS7 score maximizes the information gathered at patient assessments and allows for efficient use of resources and time. ${ }^{2-4}$

\section{New recommendations for treatment}

The treatment goal in all types of urticaria is complete relief of pruritus, whealing and swelling (Figure 3). Treatment continues until the disease remits. Exacerbating factors, including emotional stress or ingestion of nonsteroidal anti-inflammatory drugs, should be minimized. ${ }^{2,3}$

\section{First-line treatment}

Second-generation $\mathrm{H}_{1}$-antihistamines, such as desloratadine or cetirizine, are recommended as the cornerstone of urticaria treatment, based on evidence from high-quality randomized controlled trials (RCTs). Evidence-based recommendations include taking a second-generation $\mathrm{H}_{1}$-antihistamine daily rather than intermittently, and not using more than one type of $\mathrm{H}_{1}$-antihistamine on the same day. ${ }^{2,3}$

First-generation, sedating $\mathrm{H}_{1}$-antihistamines are used empirically, as most of them were introduced before the era of RCTs. They are no longer recommended for use in chronic urticaria. ${ }^{2,3}$ Their potential adverse effects include reduction of rapid eye movement-sleep and impairment of cognitive function, including learning and memory. In patients with urticaria, the widespread belief that sleep is aided by addition of a sedating first-generation $\mathrm{H}_{1}$-antihistamine such as hydroxyzine at bedtime is not supported by the available evidence. ${ }^{5,6}$

\section{Second-line treatment}

Findings from RCTs have shown that daily treatment with two to four times the licensed dose of many second-generation $\mathrm{H}_{1}$-antihistamines increases efficacy without increasing adverse events. ${ }^{2,3,7-9}$ If this fails, the addition of montelukast for three to four weeks is recommended, although this is based on RCTs showing minimal benefit. ${ }^{2,3,10,11}$ The use of $\mathrm{H}_{2}$-antihistamines is no longer recommended: a Cochrane review found that the evidence for their use consisted of old studies with high or unclear risk of bias. ${ }^{2,10,11}$

\section{Refractory chronic spontaneous urticaria}

Chronic spontaneous urticaria that fails to respond to second-line treatment needs additional pharmacotherapy. Many medications previously used as third-line treatment are no longer recommended for treatment of refractory chronic spontaneous urticaria. ${ }^{2,3,10,11}$ Use of most thirdline medications was based on case series (e.g., for sulfasalazine, methotrexate, colchicine, tacro- limus, mycophenolate and intravenous immune globulin) or on small RCTs (e.g., for hydroxychloroquine and dapsone). Several RCTs have shown efficacy of cyclosporine; however, because of potential nephrotoxic effects, patients taking cyclosporine require regular monitoring of blood pressure, renal function and cyclosporine levels. ${ }^{2,3,10,11}$

Omalizumab, an anti-IgE monoclonal antibody, is the best studied medication for severe chronic spontaneous urticaria refractory to $\mathrm{H}_{1}$-antihistamine treatment. It was licensed in 2014 on the basis of findings from five large, methodologically sound RCTs. ${ }^{12-14}$ In these studies, omalizumab doses of $300 \mathrm{mg}, 150 \mathrm{mg}$ and $75 \mathrm{mg}$ given by subcutaneous injection every four weeks were significantly more effective than placebo. The 300-mg dose was significantly more effective than the 150-mg dose, and both of these doses were more effective than the 75-mg dose in relieving itching and whealing. Dosing was not based on patient weight or total IgE level, in contrast to omalizumab dosing for severe persistent asthma. ${ }^{12-14}$ In these RCTs, the proportion of patients who had one or more

\begin{tabular}{|lll|}
\hline Box 1: Urticaria Activity Score (UAS7)* \\
\hline Score & \multicolumn{1}{|l|}{ Wheals } & \multicolumn{1}{l|}{ Pruritus } \\
\hline 0 & None & None \\
\hline 1 & Mild (<20 wheals/24 h) & $\begin{array}{l}\text { Mild (present but not annoying } \\
\text { or troublesome) }\end{array}$ \\
\hline 2 & Moderate (20-50 wheals/24 h) & $\begin{array}{l}\text { Moderate (troublesome but } \\
\text { does not interfere with normal } \\
\text { daily activity or sleep) }\end{array}$ \\
\hline 3 & $\begin{array}{l}\text { Intense }(>50 \text { wheals/24 h or } \\
\text { large confluent areas of } \\
\text { wheals) }\end{array}$ & $\begin{array}{l}\text { Intense (severe pruritus, } \\
\text { sufficiently troublesome that it } \\
\text { interferes with normal daily } \\
\text { activity or sleep) }\end{array}$ \\
\hline $\begin{array}{l}\text { *The UAS7 score is used to assess disease activity in patients with chronic spontaneous } \\
\text { urticaria. The maximum daily score is 6. The maximum weekly score is 42. Access the UAS7 at } \\
\text { http://urticaria.org.br/informacoes-uteis/uas/?lang=en. }\end{array}$ \\
\hline
\end{tabular}

Box 2: Classification of chronic urticaria*1

Chronic spontaneous urticaria

- Lasting more than six weeks

Inducible urticaria

- Occurs in response to an identifiable trigger

Subtypes of chronic urticaria:

- Physical urticaria (dermographism, cold urticaria, delayed pressure urticaria, solar urticaria, heat urticaria, vibratory angioedema)

- Cholinergic urticaria (hives from sweating, exercise or anxiety)

- Contact urticaria

- Aquagenic urticaria

*Urticaria presents with itchy wheals that may or may not be accompanied by swelling. Acute urticaria lasts less than six weeks. 


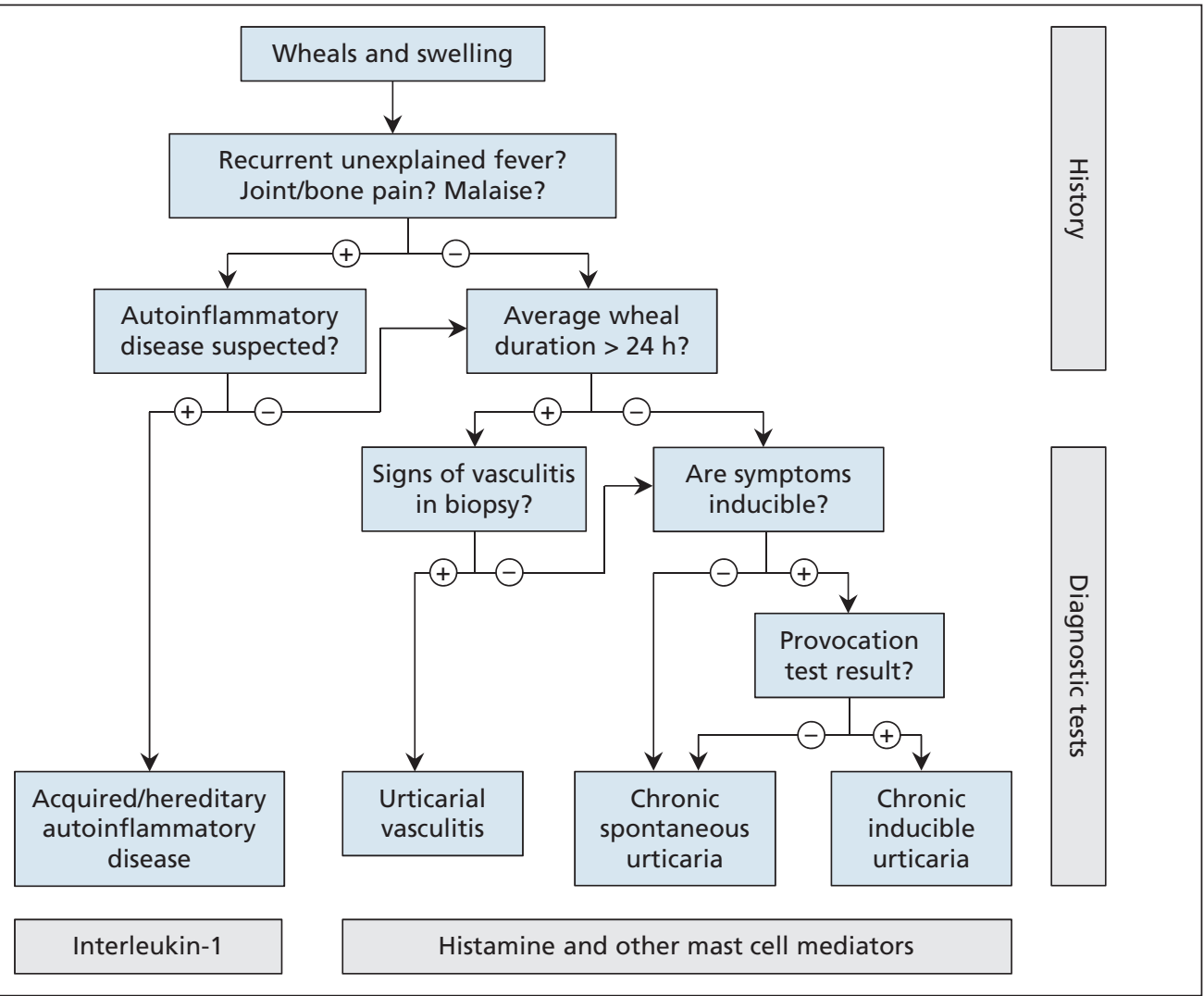

Figure 2: Algorithm for differential diagnosis of wheals and swelling. Adapted, with permission, from Zuberbier and colleagues. ${ }^{3}$

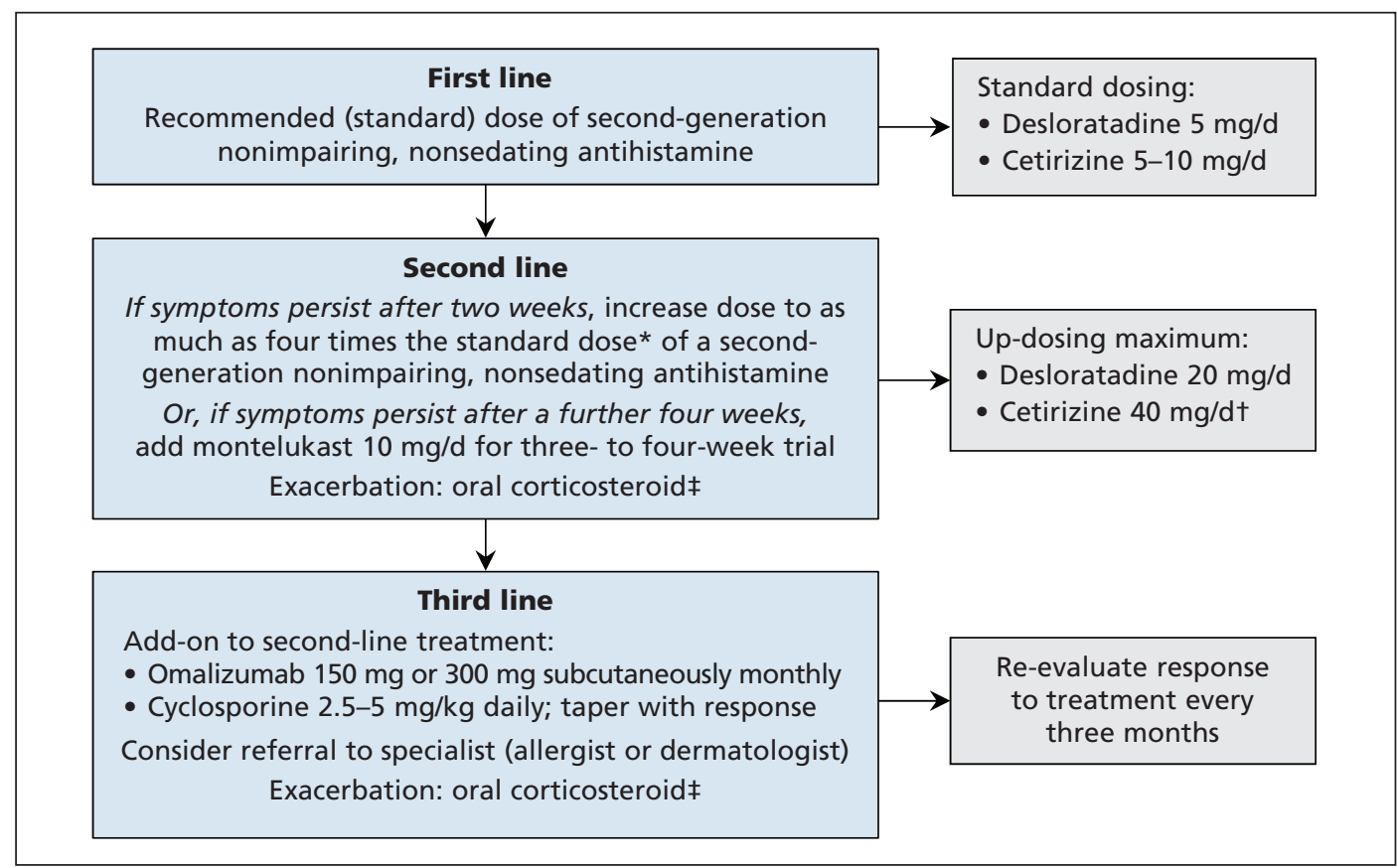

Figure 3: Algorithm for the treatment of chronic spontaneous urticaria. ${ }^{3}$ Available evidence does not support use of first-generation impairing, sedating $\mathrm{H}_{1}$-antihistamines, $\mathrm{H}_{2}$-antihistamines or monotherapy with montelukast. The only anti-inflammatory or immunosuppressant agents that have been appropriately evaluated in randomized controlled trials are omalizumab and cyclosporine (see text for details). *Increase the standard dose to up to $\mathbf{4 0 ~} \mathrm{mg}$ of cetirizine or $\mathbf{2 0} \mathrm{mg}$ of desloratadine if there is no response. tCan cause sedation at higher doses. ¥Oral corticosteroid such as prednisone $0.3-0.5 \mathrm{mg} / \mathrm{kg}$ or equivalent, for a maximum of 2-4 weeks, with tapering. Adapted, with permission, from Zuberbier and colleagues. ${ }^{3}$ 
adverse events was similar across all treatment groups, including the placebo group. Anaphylaxis was not reported, ${ }^{12-15}$ in contrast to anaphylaxis reported after omalizumab injection in patients with asthma.

The mechanism of action of omalizumab in chronic spontaneous urticaria is related to its ability to decrease free $\operatorname{IgE}$ in the blood and interstitial space and prevent IgE binding to mast cells without cross-linking of the high-affinity $\mathrm{IgE}$ receptor. This action reduces the proliferation and survival of mast cells, increases the threshold for release of mediators from mast cells, and reduces the ability of mast cells to synthesize and store de novo mediators of inflammation. ${ }^{16}$

In the clinical setting, omalizumab $150 \mathrm{mg}$ subcutaneously induces complete remission in about $30 \%$ of patients with severe chronic spontaneous urticaria after the first dose, and in as many as $70 \%$ after additional doses. Monthly doses are required to maintain disease control in most patients. ${ }^{17}$

Omalizumab is currently indicated for chronic spontaneous urticaria refractory to $\mathrm{H}_{1}$-antihistamine treatment in patients 12 years of age and older; however, it has also been shown to induce remission in children. ${ }^{18}$

For rescue medication during severe exacerbations of chronic spontaneous urticaria, an orally administered corticosteroid, such as prednisone, should be prescribed for short-term use.

Cyclosporine is recommended as a relatively low-cost third-line treatment alternative to omalizumab. ${ }^{2,3,10,11}$ Given the high cost of omalizumab injections and the potential long-term morbidity of chronic spontaneous urticaria refractory to $\mathrm{H}_{1}$-antihistamine treatment, costbenefit studies evaluating direct and indirect costs of omalizumab treatment compared with cyclosporine and other interventions are urgently needed.

\section{References}

1. Maurer M, Bindslev-Jensen C, Gimenez-Arnau A, et al. Chronic idiopathic urticaria is no longer idiopathic: Time for an update! Br J Dermatol 2013;168:455-6.

2. Zuberbier T, Aberer W, Asero R, et al. Methods report on the development of the 2013 revision and update of the EAACI/ $\mathrm{GA}^{2} \mathrm{LEN} / \mathrm{EDF} / \mathrm{WAO}$ guideline for the definition, classification, diagnosis, and management of urticaria. Allergy 2014;69:e1-29.

3. Zuberbier T, Aberer W, Asero R, et al. The EAACI/GA ${ }^{2} L E N /$ $\mathrm{EDF} / \mathrm{WAO}$ guideline for the definition, classification, diagnosis and management of urticaria: the 2013 revision and update. Allergy 2014;69:868-87.

4. Mlynek A, Zalewska-Janowska A, Martus P, et al. How to assess disease activity in patients with chronic urticaria? Allergy 2008;63:777-80.

5. Simons FER, Simons KJ. Histamine and $\mathrm{H}_{1}$-antihistamines: celebrating a century of progress. J Allergy Clin Immunol 2011; 128:1139-50.e4

6. Staevska M, Gugutkova M, Lazarova C, et al. Night-time sedating $\mathrm{H}_{1}$-antihistamine increases daytime somnolence but not treatment efficacy in chronic spontaneous urticaria: a randomized controlled trial. Br J Dermatol 2014;171:148-54.
7. Kavosh ER, Khan DA. Second-generation $\mathrm{H}_{1}$-antihistamines in chronic urticaria: an evidence-based review. Am J Clin Dermatol 2011;12:361-76.

8. Sharma $\mathrm{M}$, Bennett $\mathrm{C}$, Cohen $\mathrm{SN}$, et al. $\mathrm{H}_{1}$-antihistamines for chronic spontaneous urticaria. Cochrane Database Syst Rev 2014;11:CD006137.

9. Staevska M, Popov TA, Kralimarkova T, et al. The effectiveness of levocetirizine and desloratadine in up to 4 times conventional doses in difficult-to-treat urticaria. J Allergy Clin Immunol 2010; 125:676-82.

10. Khan DA. Alternative agents in refractory chronic urticaria: evidence and considerations on their selection and use. J Allergy Clin Immunol Pract 2013;1:433-40.e1.

11. Mitchell S, Balp MM, Samuel M, et al. Systematic review of treatments for chronic spontaneous urticaria with inadequate response to licensed first-line treatments. Int J Dermatol 2015;54:1088-104.

12. Maurer M, Rosen K, Hsieh H-J, et al. Omalizumab for the treatment of chronic idiopathic or spontaneous urticaria. $N$ Engl J Med 2013;368:924-35.

13. Kaplan A, Ledford D, Ashby M, et al. Omalizumab in patients with symptomatic chronic idiopathic/spontaneous urticaria despite standard combination therapy. J Allergy Clin Immunol 2013;132:101-9.

14. Saini SS, Bindslev-Jensen C, Maurer M, et al. Efficacy and safety of omalizumab in patients with chronic idiopathic/spontaneous urticaria who remain symptomatic on $\mathrm{H}_{1}$-antihistamines: a randomized, placebo-controlled study. J Invest Dermatol 2015;135: 67-75.

15. Urgert MC, van den Elzen MT, Knulst AC, et al. Omalizumab in patients with spontaneous urticaria: a systematic review and GRADE assessment. Br J Dermatol 2015;173:404-15.

16. Chang TW, Chen C, Lin CJ, et al. The potential pharmacologic mechanisms of omalizumab in patients with chronic spontaneous urticaria. J Allergy Clin Immunol 2015;135:337-42.

17. Sussman G, Hebert J, Barron C, et al. Real-life experiences with omalizumab for the treatment of chronic urticaria. Ann Allergy Asthma Immunol 2014;112:170-4.

18. Netchiporouk E, Nguyen $\mathrm{CH}$, Thuraisingham T, et al. Management of pediatric chronic spontaneous and physical urticaria patients with omalizumab: case series. Pediatr Allergy Immunol 2015;26:585-8

Affiliations: Department of Clinical Immunology and Allergy, and Department of Medicine (Sussman), University of Toronto, Toronto, Ont.; Centre de recherche appliqué en allergie de Quebec and Centre hospitalier de l'Université Laval (Hebert), Québec, Que.; Department of Pediatrics and Child Health, and Department of Immunology (Simons), University of Manitoba, Winnipeg, Man.

Contributors: Gordon Sussman and F. Estelle Simons played leadership roles in the project and acted to ensure the quality and coherence of the manuscript. Gordon Sussman prepared the first draft of the manuscript, and all of the authors revised it critically for important intellectual content. All of the authors approved the final version to be published and agreed to act as guarantors of the work.

Acknowledgements: The authors acknowledge the secretarial assistance provided by Lori McNiven, Health Sciences Centre, Winnipeg, Man., and Corey Saperia, Gordon Sussman Clinical Research, Inc., Toronto, Ont.

The section Cases presents brief case reports that convey clear, practical lessons. Preference is given to common presentations of important rare conditions, and important unusual presentations of common problems. Articles start with a case presentation (500 words maximum), and a discussion of the underlying condition follows (1000 words maximum). Visual elements (e.g., tables of the differential diagnosis, clinical features or diagnostic approach) are encouraged. Consent from patients for publication of their story is a necessity. See information for authors at www.cmaj.ca. 